\title{
Dominant rams lose out by sperm depletion
}

\section{A waning success in siring counters a ram's high score in competition for ewes.}

M ale traits such as large body size and weaponry are thought to have evolved to aid males contesting for access to females ${ }^{1}$. But in species where females copulate with many males in a single reproductive cycle, sperm also compete in the female's reproductive tract to fertilize $\mathrm{ova}^{2}$. Both types of competition occur in the promiscuously mating feral Soay sheep (Ovis aries) found on the island group of St Kilda, Scotland ${ }^{3,4}$. Here we show that constraints on sperm production mean that those males that are most successful in overt contests can become ineffectual in covert sperm competition.

Sperm competition is commonplace in mammals ${ }^{5}$. In feral Soay sheep, females have been recorded copulating with seven or more different males during their twoday oestrus (our unpublished results). The importance of sperm competition in this population is shown by paternity analyses revealing that $74 \%$ of Soay twins are sired by different males ${ }^{4}$. Soay males copulate up to 13 times a day ${ }^{3}$ and have a very high testes:body mass ratio ${ }^{6}$ — both adaptations for sperm competition ${ }^{7}$.

Soay rams compete fiercely for access to females in oestrus, butting the flanks of opponents (seen in 29\% of 722 focal watches) or clashing head-on (15\% of watches). Examination of skeletons has revealed that some $60 \%$ of Soay rams suffer fractures of the cervical vertebrae, presumably as a result of these fights ${ }^{8}$.

Moreover, analysis of the determinants of male copulation rate over the rut (and hence ability to gain access to receptive females) indicates the advantage of greater skeletal and horn size (Table 1, overleaf). Males with large bodies and horns copulated more than smaller competitors as the rut progressed (Fig. 1a; hindleg length:week of rut, Table 1). Although horns and other weaponry are frequently proposed as targets of sexual selection ${ }^{1}$, rarely, if ever, have they been shown to increase reproductive success in mammals irrespective of age and body size. In our analysis, however, we control for body size and discount the effect of age per se, which is not significant $(P>0.2)$.

The behavioural success of larger males translates into greater reproductive success (more lambs sired; Table 1). But as the rutting season progressed and their copulation frequency increased, there was a decline in the proportion of lambs they sired (Table 1, hindleg length:week of lambing; Fig. 1b). This mismatch between copulation rate and siring success is difficult to explain in terms other than of sperm depletion.

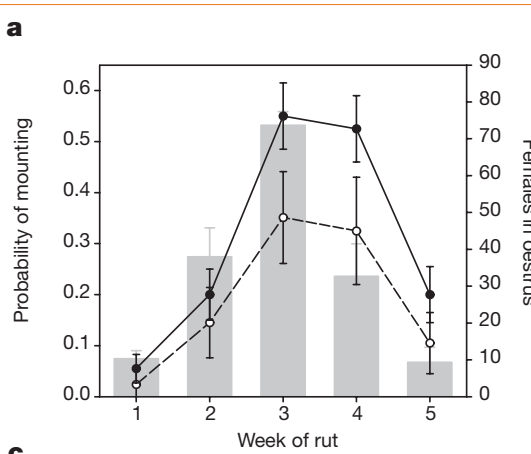

c
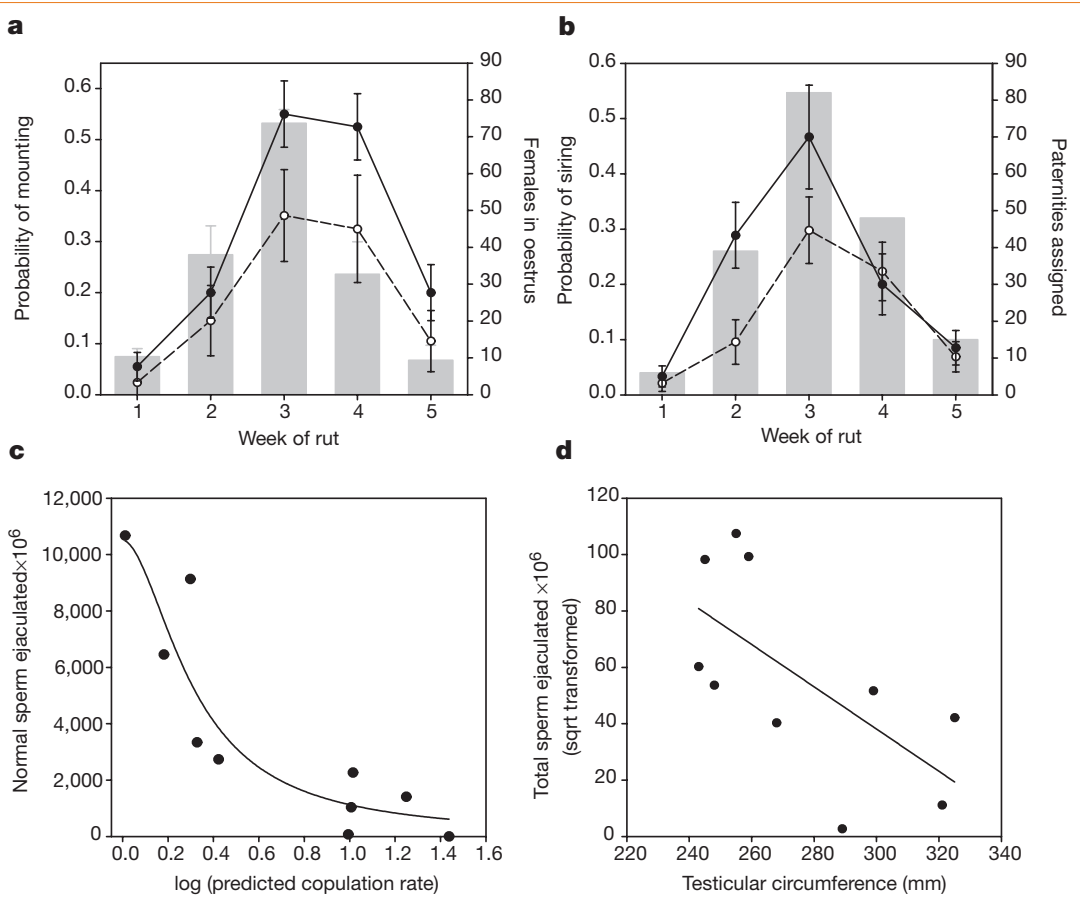

Figure 1 Evidence for sperm depletion in Soay sheep rams. a, Temporal variation in the mean probability $( \pm$ s.e.) of being observed mounting during a watch in each week for males with above- $(\bullet)$ and below-average $(\bigcirc)$ hindleg lengths in each year. Bars, mean number of females in oestrus that week ( \pm s.e.). b. Temporal variation in the mean probability ( \pm s.e.) of being assigned a paternity in a given week for males with above- $(-)$ and below-average $(\bigcirc)$ hindleg lengths in each year. Bars indicate the total number of paternities assigned to lambs conceived during that week. c, Number of normal sperm ejaculated by rams in relation to their predicted copulation rate. Copulation rates were predicted from the male's horn and hindleg length using parameter estimates from the generalized linear mixed model (Table 1); this provides an index of overt competitive ability. Fitted logistic curve: $10508.9 /\left[1+\left(\log x / \log x_{0.3128}\right)^{1.8235}\right]$, where $x$ is the copulation rate; $F=16.475, n=10, P=0.0023$, adjusted $r^{2}=77.5 \%$. d, Total number of sperm ejaculated (square-root transformed) in relation to testicular circumference. Linear regression: $262.9-\left(0.8 \times\right.$ testicular circumference), $F=5.858, n=10, P<0.05$, adjusted $r^{2}=35.1 \%$. Single ejaculates were collected from natural matings of Soay rams using an intra-vaginal device ${ }^{10}$. Collections were made between 20 November 1999 and 26 November 1999, in the last two weeks of the rut. Collections prior to this were not logistically feasible.

At its simplest, sperm competition functions as a lottery: the more tickets bought (the more sperm inseminated) the greater the chance of 'winning', in this case gaining a paternity ${ }^{7}$. This mechanism is thought to have selected for the high copulation rates ${ }^{5,7}$ and large testes ${ }^{7}$, as found in mammal species in which sperm competition occurs. The high copulation rates and greater success of large males could result in a widening gap in the sperm that large and small males have available for ejaculates ${ }^{7}$.

Evidence for constrained sperm production comes from domestic sheep ${ }^{9,10}$. Merino rams that were electro-ejaculated 8 times per day for 18 days showed a decline in sperm numbers per ejaculate of over $85 \%$ (ref. 9). We believe that large Soay rams copulating up to 13 times per day $^{3}$ become increasingly depleted of sperm as the mating season progresses. This results in the sperm in their ejaculates being outnumbered during sperm competition by those of behaviourally subordinate males with relatively intact sperm reserves, explaining the fall in siring success of larger males.

Ejaculates collected during the later stages of the rut showed that large, frequently copulating males transferred fewer sperm per ejaculate (Fig. 1c), a greater proportion of which were abnormal (Spearman rank correlation between numbers of sperm ejaculated and per cent of abnormal sperm was $-0.770 ; t=-3.410, n=10$, $P=0.01)$. One of the 10 ejaculates contained under $60 \times 10^{6}$ sperm; in domestic sheep, conception rates drop by more than $60 \%$ below this threshold ${ }^{11}$.

It could be argued that the lower siring success of large males towards the end of the rut is due to differential investment in sperm production $^{2}$, with larger males always producing fewer sperm, rather than to a depletion of sperm reserves, but we believe this is highly unlikely. In mammals, there is widespread evidence for testicular size 


\begin{tabular}{|c|c|c|c|c|c|}
\hline Term & d.f. & Effect & s.e. & Wald statistic $\left(\chi^{2}\right)$ & $P$ \\
\hline \multicolumn{6}{|c|}{$\begin{array}{l}\text { Male copulatory success* } \\
\text { Watch duration }\end{array}$} \\
\hline \multicolumn{6}{|l|}{$\begin{array}{l}\text { No. of females } \\
\text { in oestrus }\end{array}$} \\
\hline \multicolumn{6}{|l|}{$\begin{array}{l}\text { No. of females } \\
\text { in oestrus }\end{array}$} \\
\hline Week of rut & 1 & -10.31 & 3.991 & 6.68 & 0.010 \\
\hline Hindleg length & 1 & -0.0844 & 0.0650 & 1.68 & 0.194 \\
\hline $\begin{array}{l}\text { Horn length } \\
\text {... }\end{array}$ & 1 & 0.00611 & 0.00228 & 7.18 & 0.007 \\
\hline Hindleg length: & 1 & 0.0559 & 0.0207 & 7.29 & 0.007 \\
\hline $\begin{array}{l}\text { Male siring succ } \\
\text { No. of females } \\
\text { lambing }\end{array}$ & 1 & 0.0556 & 0.00810 & 47.01 & $<0.001$ \\
\hline $\begin{array}{l}\text { No. of females } \\
\text { lambing }^{2}\end{array}$ & 1 & -0.000293 & 0.0000725 & 16.32 & $<0.001$ \\
\hline \multicolumn{4}{|l|}{ Week of } & 9.49 & 0.002 \\
\hline Hindleg length & 1 & 0.119 & 0.0331 & 12.83 & $<0.001$ \\
\hline Horn length & 1 & 0.00767 & 0.00168 & 20.85 & $<0.001$ \\
\hline $\begin{array}{l}\text { Hindleg length: } \\
\text { week of lambing }\end{array}$ & 1 & -0.0258 & 0.00865 & 8.85 & 0.003 \\
\hline \multicolumn{6}{|c|}{$\begin{array}{l}\text { We analysed temporal behavioural and paternity data using generalized linear mixed models with a logit link function. These control for repeated measures } \\
\text { of behaviour and paternity by fitting male identity and year as random effects }{ }^{12} \text {. A colon between terms denotes two-way interactions. } \\
\text { *Minimal model of male copulatory success. The response is binary, indicating whether a mounting attempt occurred during a focal watch performed in } \\
1996-98 ; n=371 \text {. Median watch duration was } 1 \mathrm{~h} \text {. } \\
\text { †Minimal model of male siring success. The response variable takes the form of binomial proportions, being the number of days in a given week on which a } \\
\text { male gains a paternity, } n=897 \text {. Includes analysis of } 170 \text { paternities assigned between } 1988 \text { and } 1999^{4} \text {. Temporal behavioural and paternity analyses can } \\
\text { be compared owing to the correspondence between conception and lambing distributions, gestation being } 151.2 \pm 1.3 \text { days (mean } \pm \text { s.d. })^{13} \text {. Hindleg length } \\
\text { is a linear indicator of skeletal size. Age, weight and basal-horn circumference were tested in each model but were excluded (all } P>0.1 \text { ). For further } \\
\text { details, see http://www.ecologynet.stir.ac.uk/kilda/depletion. }\end{array}$} \\
\hline
\end{tabular}

determining sperm production rate $^{7}$, yet we find a negative correlation between testicular circumference and number of sperm ejaculated (Fig. 1d). This suggests that males producing smaller ejaculates towards the end of the rut had greater capacity for ejaculate production at the start of it. To our knowledge, this is the first demonstration that limitations on ejaculate production may constrain male reproductive success in a wild vertebrate population.

Brian T. Preston*, Ian R. Stevenson*, Josephine M. Pemberton $\dagger$, Kenneth Wilson ${ }^{\star}$ ${ }^{\star}$ Institute of Biological Sciences, University of Stirling, Stirling FK9 4LA, UK

e-mail: b.t.preston@stir.ac.uk

$\dagger$ Institute of Cell, Animal and Population Biology, University of Edinburgh, West Mains Road,

Edinburgh EH9 3JT, UK

1. Andersson, M. Sexual Selection (Princeton Univ. Press, 1994).

\section{Biotechnology}

\section{Transgenic crops in natural habitats}

1though improved crop yields can be engineered by genetically modifying plants, there is ecological concern over whether these plants are likely to persist in the wild in the event of dispersal from their cultivated habitat. Here we present the results of a long-term study of the performance of transgenic crops in natural habitats. Four different crops (oilseed rape, potato, maize and sugar beet) were grown in 12
2. Parker, G. A. Proc. R. Soc. Lond. B 242, 120-126 (1990).

3. Grubb, P. in Island Survivors: The Ecology of the Soay Sheep of St. Kilda (eds Jewell, P. A., Milner, C. \& Boyd, J. M.) 195-223 (Athlone, London, 1974)

4. Pemberton, J. M., Coltman, D. W., Smith, J. A. \& Pilkington, J. G. Biol. J. Linn. Soc. 68, 289-301 (1999).

5. Møller, A. P \& Birkhead, T. R. Biol. J. Linn. Soc. 38, 119-132 (1989)

6. Stevenson, I. R. Male-biased Mortality in Soay Sheep. Thesis, Univ. Cambridge (1994).

7. Gomendio, M., Harcourt, A. H. \& Roldan, E. R. S. in Sperm Competition and Sexual Selection (eds Birkhead, T. R. \& Møller, A. P.) 667-756 (Academic, San Diego, 1998).

8. Clutton-Brock, J., Dennis-Bryan, K. \& Armitage, P. L. Bull. Br. Mus. Nat. Hist. (Zool.) 56, 1-56 (1990).

9. Thwaites, C. J. Anim. Reprod. Sci. 37, 299-309 (1994).

10. Synnot, A. L., Fulkerson, W. J. \& Lindsay, D. R. J. Reprod. Fertil. 61, 355-361 (1981).

11. Fulkerson, W. J., Synnott, A. L. \& Lindsay, D. R. J. Reprod. Fert. 66, 129-132 (1982).

12. Genstat 5 Committee Genstat 5 (Release 3) Reference Manual (Clarendon, Oxford, 1993).

13. Jewell, P. A. \& Grubb, P. in Island Survivors: The Ecology of the Soay Sheep of St. Kilda (eds Jewell, P. A., Milner, C. \& Boyd, J. M.) 224-241 (Athlone, London, 1974).

different habitats and monitored over a period of 10 years. In no case were the genetically modified plants found to be more invasive or more persistent than their conventional counterparts.

In the late 1980s, there were three conjectural risks associated with genetically modified (GM) crops: that they would become weeds of agriculture or invasive of natural habitats; that the introduced genes would be transferred by pollen to wild relabecome more weedy or invasive; or that GM plants would be a direct hazard to humans, domestic livestock or beneficial

^ ๑) 2001 Macmillan Magazines Ltd tives, whose hybrid offspring would then wild organisms, for example by being toxic or allergenic. Our study assesses the grounds for the first two of these fears.

We have shown previously that GM oilseed-rape plants did not perform better or persist for longer than conventional plants over a 3-year period ${ }^{1}$. We now compare the results of monitoring conventional and GM lines of four crop species over 10 years ${ }^{2,3}$ in a field experiment conducted in 12 different habitats (four in each of Cornwall, Sutherland and Berkshire in the United Kingdom) and repeated in the years 1990, 1991 and 1992 in order to determine whether GM crops would be more invasive or more persistent in natural habitats than non-GM crops. We tested all the crop species and GM constructs that were available in 1990: oilseed-rape and maize plants expressing tolerance of the herbicide glufosinate, sugar beet tolerant of glyphosate ('Roundup'), and two types of GM potato expressing either the insecticidal Bt toxin or pea lectin.

The sites were monitored each year to follow the fate of sown individuals, to measure recruitment onto unsown areas nearby, and to determine whether there was any resurgence following natural disturbance in later years. Figure 1 shows the fraction of seeds sown (or tubers planted) that produced mature plants at the end of the first growing season. We found that there were no significant differences in average recruitment between conventional and GM plants for any of the four crops (full details and significance tests are provided in Supplementary Information). None of the crops, GM or conventional, increased in abundance at any of the sites.

Population sizes of all crops declined after the first year as a result of increased competition from native perennial plants. In no case did the GM lines persist for significantly longer than their conventional counterparts. For oilseed rape, seedling establishment was significantly lower for GM plants compared with conventional lines in six out of 12 cases, and were not significantly greater in any case. Subsequent survival was significantly lower for GM lines in three out of 12 cases and significantly higher in two cases. For maize, seedling establishment was significantly lower for the GM line in two out of 12 cases, and significantly greater in no case. Subsequent survival was significantly higher for the GM line in one case, but all lines were extinct by the beginning of the second year.

For potato, survival of planted tubers to the end of the first growing season was significantly lower for GM lines in one case out of eight, and significantly higher in one instance. The few cases of increased GMplant survival that were significant in the short term did not translate into long-term differences in persistence (see Supplementary Information). Survival of perennating 